\title{
Correlation between immune-related adverse events and prognosis in patients with various cancers treated with anti PD-1 antibody
}

Hiroshi Matsuoka ${ }^{1 *}$ DD, Takahiro Hayashi ${ }^{2}$, Karen Takigami ${ }^{2}$, Kazuyoshi Imaizumi ${ }^{3}$, Ryoichi Shiroki ${ }^{4}$, Naoki Ohmiya $^{5}$, Kazumitsu Sugiura ${ }^{6}$, Kenji Kawada ${ }^{7}$, Akira Sawaki ${ }^{7}$, Koutaro Maeda ${ }^{8}$, Yousuke Ando $^{9}$ and Ichiro Uyama ${ }^{1}$

\begin{abstract}
Background: Immune checkpoint inhibitors (ICls) targeting programmed cell death protein 1 (PD-1) are used for the treatment of various cancer types. However, immune-related adverse events (irAEs) occur in patients treated with ICls. Several small-scale studies have reported the onset of irAEs and therapeutic effects of ICls. Here we report a large-scale retrospective study covering a wide range of cancers. We evaluated irAEs and the therapeutic effects of ICls and determined whether irAEs could be predicted.
\end{abstract}

Methods: This study included patients treated with the anti-PD-1 antibodies nivolumab or pembrolizumab at Fujita Health University Hospital between December 2015 and March 2019. We retrospectively reviewed the electronic medical records for age, cancer type, pre-treatment blood test data, presence or absence of irAE onset, type and severity of irAEs, outcome of irAE treatment, response rate, progression-free survival and overall survival.

Results: Two hundred-eighty patients received ICls. The overall incidence of irAEs was 41.1\% (115 patients), and the incidence of severe irAEs of grade 3 and higher was 2.8\% (eight patients). The most common irAEs were skin disorders, thyroid disorders and interstitial pneumonitis. Patients with irAEs were significantly older than those without irAEs (69.7 versus 66.0 years, $P=0.02$ ). The objective response rate (ORR) in patients with irAEs was $30.4 \%$, which was significantly higher than in patients without irAEs (12.7\%; $P<0.01)$. Both the median overall and progression-free survival were significantly longer in patients with irAEs $(P<0.01, p<0.01)$. Based on the blood test data obtained before $\mathrm{ICI}$ therapy, hypothyroidism, thyroid-stimulating hormone levels and thyroglobulin antibody levels were associated with the onset of irAEs. In many patients with irAEs of Common Terminology Criteria for Adverse Events Grade 3 or higher, re-administration of ICls was difficult, and their outcomes were poor. In contrast, many patients with irAEs of a lower grade were able to resume $\mathrm{ICl}$ therapy.

Conclusion: Although the onset of irAEs was difficult to be predicted based on pre-treatment tests. It appeared that the continuation of $\mathrm{ICI}$ therapy, along with early detection and adequate control of irAEs, might contribute to the improved prognosis of patients.

Keywords: Immune-related adverse events, Programmed cell death-1, Nivolumab, Pembrolizumab

\footnotetext{
*Correspondence: mats1025@fujita-hu.ac.jp

'Department of Surgery Fujita Health University, Dengakugakubo 1-98, Kutsukake-cho, Toyoake City, Aichi, Japan

Full list of author information is available at the end of the article
}

(C) The Author(s). 2020 Open Access This article is licensed under a Creative Commons Attribution 4.0 International License, which permits use, sharing, adaptation, distribution and reproduction in any medium or format, as long as you give appropriate credit to the original author(s) and the source, provide a link to the Creative Commons licence, and indicate if changes were made. The images or other third party material in this article are included in the article's Creative Commons licence, unless indicated otherwise in a credit line to the material. If material is not included in the article's Creative Commons licence and your intended use is not permitted by statutory regulation or exceeds the permitted use, you will need to obtain permission directly from the copyright holder. To view a copy of this licence, visit http://creativecommons.org/licenses/by/4.0/ The Creative Commons Public Domain Dedication waiver (http://creativecommons.org/publicdomain/zero/1.0/) applies to the data made available in this article, unless otherwise stated in a credit line to the data. 


\section{Background}

The anti-programmed cell death protein 1 (PD-1) antibodies nivolumab and pembrolizumab are immune checkpoint inhibitors (ICIs) that activate the anti-tumour cytotoxic activity of $\mathrm{T}$ cells by inhibiting the binding of the PD-1 receptor and programmed cell death protein ligand 1 (PD-L1). They are currently used for the treatment of a wide range of cancers [1]. However, the overall response rate is low $[2,3], \mathrm{PD}-1$ and $\mathrm{PD}-\mathrm{L} 1$ signaling disruption by ICIs regenerates $\mathrm{T}$-cell-mediated anti tumor immunity, producing durable anticancer effects in a subset of patients.

Their associated adverse events are also unique and are termed as immune-related adverse events (irAEs), which are different from the events observed in patients treated with conventional anti-tumour agents. In some cases, irAEs are serious and can even result in death [4]. irAEs attracted attention soon after the approval of ICIs, and since then, several reports have been published [5-7]. Although symptoms such as type 1 diabetes mellitus and severe diarrhoea had attracted attention, recent reports have indicated that the onset of irAEs contributes to the prognosis of patients [8-13]. However, many of the reports describe studies on malignant melanoma and lung cancer, for which ICIs were used ahead of the use for other cancers. The sample sizes in the reports on malignant melanoma are small, and only small-scale studies have been reported on lung cancer. In the present study that involved a larger number of patients treated with anti-PD-1 antibodies for a wide range of cancers, we retrospectively investigated irAEs and therapeutic effects and determined whether the onset of irAEs could be predicted.

\section{Methods}

\section{Study approval}

The present study was reviewed and approved by the Ethics Committee of Fujita Health University (HM19-209). Informed consent was obtained from the eligible patients by an opt-out procedure. Using electronic medical records, we retrospectively evaluated patient characteristics (i.e. age, sex and Eastern Cooperative Oncology Group (ECOG) Performance Status (PS)), pre-treatment blood test data, presence or absence of irAE onset, the timing of irAE onset, the severity of irAEs, progression-free survival (PFS), overall survival (OS) and objective response to treatment.

\section{Patient characteristics}

The patients were divided into two groups: the irAE group and the non-irAE group. Side effects with a high probability of having an underlying immunological basis, as documented by the treating provider and warranting frequent monitoring or potential intervention, were labeled as irAE.To determine the association of irAEs with the patient characteristics and pre-treatment test data, the survival times of the patients in these groups were compared. Moreover, the treatment and outcomes after the onset of irAEs, as well as differences among cancer types, were examined.

\section{Treatment and assessment}

Nivolumab was administered via an intravenous infusion at a dose of $3 \mathrm{mg} / \mathrm{kg}$ every 2 weeks until August 2018 and after then, at a dose of $240 \mathrm{mg} /$ bodyweight every 2 week according to recommended dosage changed. Pembrolizumab was administered at a dose of $200 \mathrm{mg} /$ bodyweight every 3 weeks.Both drugs were administered until disease progression or the onset of uncontrollable adverse events. Adverse events were assessed according to the National Cancer Institute-Common Toxicity Criteria (NCI-CTC) version 4.03. Clinical response to treatment was categorized as either complete response (CR), partial response (PR), stable disease (SD), or progressive disease (PD) according to the Response Evaluation Criteria in Solid Tumors (RECIST) version 1.1. Although the timing of computed tomography analysis varied among cancer types, it was generally performed every 6-10 weeks. The baseline was adopted at the start point of ICI treatment. The measurable lesions were evaluated by the criteria of RECIST. Images of best response during the entire treatment period was used for this evaluation. Unsuitable for evaluation (e.g. loss of CT date or poorly timed examination) were clinically evaluated by corresponding clinician, we adopted the radiologist's report and the doctor's record for evaluation. Otherwise, the investigator made a discussion directly with the doctor to evaluate the clinical effect. The best overall response rates (ORR) were based on combining $\mathrm{CR}$ and PR disease response, DCR was based on combining $C R, P R$ and $S D$ disease response.

PFS was defined as the time from the start of immunotherapy to the date of disease progression or death, whichever occurred first. Patients who were alive without disease progression were censored on the date of last scan. OS was defined as the time from the start of immunotherapy to death Patients who were still alive were censored at the date of the last contact. Survival analysis was performed in November 2019, 8 months after the final enrollment of eligible patients.

\section{Statistical analysis}

To compare the two groups, a t-test was performed for normally distributed data, and Mann-Whitney U and chi-square tests were performed for the other data. PFS and OS were compared using the Kaplan-Meier method and the log-rank test. The objective response rate (ORR) was defined as the best response after the initiation of the anti-PD-1 antibody therapy. The analysis software used was SPSS. In all analyses, a $P$-value of $<0.05$ was considered to indicate a significant difference. 


\section{Results}

\section{Patient characteristics}

Anti-PD-1 antibody therapy was administered to 280 patients with advanced cancer. The median age at the time of treatment was 67.5 (22-88) years, and the male-to-female ratio was 3:1. There were 59 patients with gastric cancer, 129 with lung cancer, 27 with renal cancer, 26 with head and neck cancer, 13 with malignant melanoma, two with Hodgkin's lymphoma, four with malignant pleural mesothelioma, 13 with bladder cancer and seven with ureteral cancer. Nivolumab was used in 179 patients and pembrolizumab was used in 101. Nivolumab was administrated as the first line in 8 patients of malignant melanoma and 1 patient of renal cancer combined with nivolumab + ipilimumab. Pembrolizumab was given 27 patients of lung cancer as the first line treatment. All Hodgkin lymphoma patients were recurrent cases.

\section{Onset of irAEs}

irAEs occurred in 115 patients (41.1\%), and grade 3 and 4 irAEs occurred in eight patients $(2.8 \%)$. The most common irAE was skin disorders (20.7\%), many of which were a rash accompanied by pruritus. The second most common irAE was thyroid disorders (10.7\%), which showed patterns of acute thyroiditis and hypothyroidism. Furthermore, interstitial pneumonitis was observed in $9.6 \%$ of the patients, many of which had lung cancer or head and neck cancer. Table 1 shows the patient characteristics according to patients with and without irAEs, and Table 2 summarises irAE symptoms. Based on consensus guidelines of American Society of Clinical Oncology [14], low grade irAE were discontinuation of ICI and follow-up, and grade 2 or higher adverse events used steroids. In addition, treatment was performed in multiple occupations by the intervention of specialists such as endocrinology and neurology. Only 1 patient used infliximab.

\section{Therapeutic effects according to the onset of irAEs}

The median age of patients was $69.7(43-88)$ in the irAE group and $66.0(22-87)$ in the non-irAE group, and the patients in the irAE group were significantly older

Table 1 Characteristics of patients with and without irAE

\begin{tabular}{|c|c|c|c|}
\hline & with irAE $(n=115)$ & without irAE $(n=165)$ & $p$ value \\
\hline Age median (range) & $69.7(43-88)$ & $66.0(22-87)$ & 0.2 \\
\hline Sex (male/female) & $90 / 25$ & $119 / 46$ & 0.25 \\
\hline ECOG PS, 0/1/>2 & $69 / 42 / 4$ & $101 / 58 / 6$ & \\
\hline preexisting autoimmune disease & 10 & 14 & 0.26 \\
\hline \multicolumn{4}{|l|}{ past regimen line (\%) } \\
\hline 1st & $27(23.5)$ & $24(14.5)$ & \\
\hline 2nd & $43(37.4)$ & $47(28.5)$ & \\
\hline $3 r d$ & $30(26.1)$ & $62(37.6)$ & \\
\hline $4 \mathrm{th}^{\sim}$ & $15(13.0)$ & $32(19.4)$ & \\
\hline \multicolumn{4}{|l|}{ origin number (\%) } \\
\hline gastric & $15(13)$ & $44(26.7)$ & $p=0.03$ \\
\hline lung & $68(59.1)$ & $61(36.9)$ & \\
\hline RCC, urothelial and bladder cancer & $19(16.5)$ & $28(17)$ & \\
\hline malignant melanoma & $5(4.3)$ & $8(4.8)$ & \\
\hline head and neck & $7(6.1)$ & $19(11.5)$ & \\
\hline reccurent Hodgikin lymphoma & $1(0.9)$ & $1(0.6)$ & \\
\hline malignant pleural mesothelioma & $0(0)$ & $4(2.4)$ & \\
\hline \multicolumn{4}{|l|}{ Best Response (number) } \\
\hline CR & 1 & 1 & \\
\hline PR & 37 & 20 & \\
\hline SD & 45 & 44 & \\
\hline PD & 32 & 98 & \\
\hline ORR(\%) & 33 & 12.7 & $<0.001$ \\
\hline DCR(\%) & 72.2 & 38.2 & $<0.001$ \\
\hline
\end{tabular}

Abbreviations: $C R$ complete response, $P R$ partial response, $S D$ stable disease, $P D$ progressive disease, $O R R$ objective response rate, $D C R$ disease control rate, $R C C$ renal cell carcinoma 
Table 2 iAE according to category and grade

\begin{tabular}{|c|c|c|c|c|}
\hline Category & Total & $\%$ & G1-2 & $\mathrm{G} 3<$ \\
\hline No, of irAE patients & 115 & 41.1 & & \\
\hline irAE cases (total) & 145 & & 137 & 8 \\
\hline Skin & 58 & 20.7 & 56 & 2 \\
\hline rash & 44 & 15.7 & & \\
\hline itching & 43 & 15.4 & & \\
\hline vitiligo & 3 & 1.1 & & \\
\hline erythema & 12 & 4.3 & & \\
\hline herpes zoster & 2 & 0.7 & & \\
\hline Gastrointestinal & 6 & 2.1 & 6 & 0 \\
\hline diarrhea & 3 & 1.1 & & \\
\hline stomatitis & 3 & 1.1 & & \\
\hline Thyroid & 30 & 10.7 & 30 & 0 \\
\hline thyroiditis & 12 & 4.3 & & \\
\hline hypothyroidism & 26 & 9.3 & & \\
\hline Hepatobiliary & 8 & 2.9 & 7 & 1 \\
\hline Renal dysfunction & 4 & 1.4 & 4 & 0 \\
\hline Pneumonitis & 27 & 9.6 & 24 & 3 \\
\hline \multicolumn{5}{|l|}{ Others } \\
\hline pituitary & 2 & 0.7 & 1 & 1 \\
\hline dabetes mellitus & 3 & 1.1 & 3 & 0 \\
\hline myositis & 1 & 0.4 & 1 & 0 \\
\hline ophthalmitis & 1 & 0.4 & 1 & 1 \\
\hline encephalitis & 1 & 0.4 & 1 & 0 \\
\hline hypoacusis & 1 & 0.4 & 1 & 0 \\
\hline amnesia & 1 & 0.4 & 1 & 0 \\
\hline neuropachy & 2 & 0.7 & 2 & 0 \\
\hline
\end{tabular}

(Table 1, $P=0.024)$. The ORR was significantly higher in the irAE group $(33.0 \%)$ than in the non-irAE group (12.7\%; $P<0.001)$. The DCRwas higher in the irAE group (72.2\%) than in the non-irAE group (38.2\%; $P<0.001)$. The median OS was 48.7 months in the irAE group and 10.7 months in the non-irAE group $(P<0.01)$. The prognosis was significantly extended in the irAE group. The median PFS was significantly longer in the irAE group (17.6 months) than in the non-irAE group (3.0 months, $p<0.01$; Fig. 1 ).

\section{Prediction of the onset of irAEs}

Table 3 summarises the results of pre-treatment blood tests according to the presence or absence of irAEs. Although no significant difference was observed in the levels of rheumatoid factors with respect to the overall incidence of irAEs, the levels were higher in the irAE group $(P=0.08)$. In addition, the lactate dehydrogenase (LDH) levels were significantly lower in the irAE group $(P=0.02)$.

When irAEs were separately evaluated according to damaged organs, many patients with thyroid disorders had low levels of thyroid-stimulating hormones (TSHs) and free thyroxine $(P=0.02$, both). Furthermore, the proportion of patients with high thyroglobulin antibody levels was higher in the irAE group $(P=0.05$; Table 4$)$.

The incidence of irAEs was also compared among different cancer types. irAEs occurred in 65 patients with lung cancer (51.1\%), and the incidence rate was significantly higher than in those with other cancer types (31.7\%) $(P<0.001)$. In contrast, irAEs occurred in 15 patients with gastric cancer (25.4\%), and the incidence rate was significantly lower than in patients with other cancer types $(45.2 \%)(P<0.01)$. When irAE symptoms were compared among cancer types, interstitial pneumonia occurred more frequently in patients with lung cancer, but no significant difference was observed

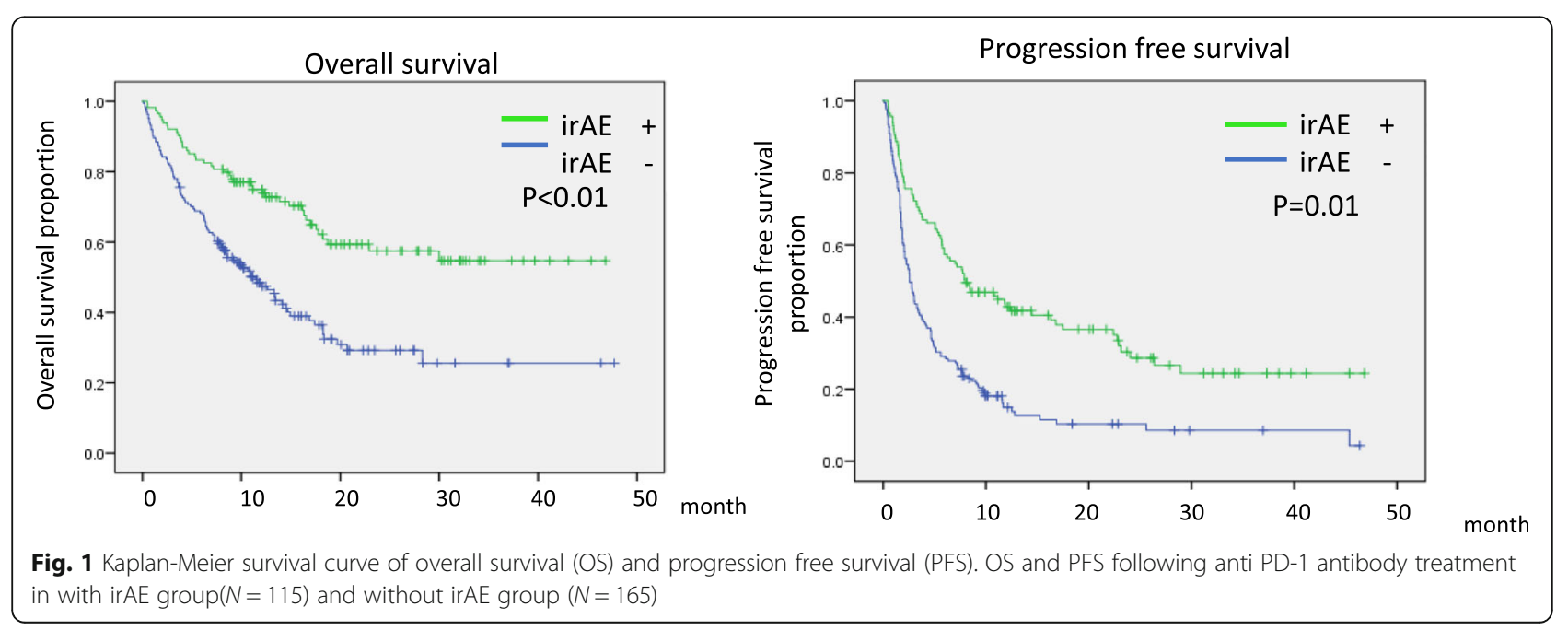


Table 3 Relationship between preexisting bood examination and irAE

\begin{tabular}{|c|c|c|c|}
\hline & $\operatorname{irAE}(-)$ & $\operatorname{irAE}(+)$ & $p$ value \\
\hline \multicolumn{4}{|l|}{$\mathrm{KL}-6$} \\
\hline$n$ & 139 & 87 & 0.7 \\
\hline $\mathrm{U} / \mathrm{mL}$ & $269(182-458)$ & $289(196-424)$ & \\
\hline \multicolumn{4}{|l|}{ ANA } \\
\hline$n$ & 131 & 84 & 0.87 \\
\hline positive rate(\%) & 38.2 & 60.7 & \\
\hline \multicolumn{4}{|l|}{$\operatorname{TgAb}$} \\
\hline$n$ & 124 & 75 & 0.22 \\
\hline $\mathrm{IU} / \mathrm{mL}$ & $0.9(0.9-0.9)$ & $0.9(0.9-5.6)$ & \\
\hline \multicolumn{4}{|l|}{ RF } \\
\hline$n$ & 115 & 80 & 0.08 \\
\hline positive rate(\%) & 12.2 & 21.3 & \\
\hline \multicolumn{4}{|l|}{ anti AChR } \\
\hline$n$ & 118 & 67 & 0.53 \\
\hline positive rate(\%) & 6.8 & 4.5 & \\
\hline \multicolumn{4}{|l|}{ TSH } \\
\hline $\mathrm{n}$ & 150 & 104 & 0.79 \\
\hline$\mu \mathrm{U} / \mathrm{mL}$ & $1.93(0.95-3.09)$ & $1.81(1.08-3.28)$ & \\
\hline \multicolumn{4}{|l|}{ FT3 } \\
\hline$n$ & 147 & 103 & 0.09 \\
\hline $\mathrm{pg} / \mathrm{mL}$ & $2.33 \pm 0.51$ & $2.44 \pm 0.48$ & \\
\hline \multicolumn{4}{|l|}{ FT4 } \\
\hline$n$ & 149 & 104 & 0.34 \\
\hline $\mathrm{ng} / \mathrm{dL}$ & $1.06(0.96-1.22)$ & $1.06(0.94-1.18)$ & \\
\hline \multicolumn{4}{|l|}{$\mathrm{ACTH}$} \\
\hline$n$ & 114 & 66 & 0.95 \\
\hline $\mathrm{pg} / \mathrm{mL}$ & $27.7(18.7-47.9)$ & $30.8(16.7-45.3)$ & \\
\hline \multicolumn{4}{|l|}{ antiTPOA } \\
\hline$n$ & 111 & 60 & 0.53 \\
\hline $\mathrm{U} / \mathrm{L}$ & $11.0(9.0-12.0)$ & $11.0(9.0-13.0)$ & \\
\hline \multicolumn{4}{|l|}{ AST } \\
\hline $\mathrm{n}$ & 162 & 115 & 1.49 \\
\hline $\mathrm{U} / \mathrm{L}$ & $21.0(16.0-28.8)$ & $21.0(17.0-28.0)$ & \\
\hline \multicolumn{4}{|l|}{ ALT } \\
\hline$n$ & 163 & 115 & 0.51 \\
\hline $\mathrm{U} / \mathrm{L}$ & $14.0(10.0-23.5)$ & $15.0(11.0-23.5)$ & \\
\hline \multicolumn{4}{|l|}{$\mathrm{LDH}$} \\
\hline$n$ & 160 & 109 & 0.02 \\
\hline $\mathrm{U} / \mathrm{L}$ & 213.5 (177.5-282.5) & $198.0(168.0-236.0)$ & \\
\hline \multicolumn{4}{|l|}{ Alb } \\
\hline$n$ & 156 & 111 & 0.2 \\
\hline $\mathrm{g} / \mathrm{dL}$ & $3.6(3.1-3.9)$ & $3.7(3.2-4.0)$ & \\
\hline \multicolumn{4}{|l|}{ CRP } \\
\hline$n$ & 162 & 110 & 0.91 \\
\hline $\mathrm{mg} / \mathrm{dL}$ & $0.52(0.11-2.27)$ & $0.46(0.17-1.86)$ & \\
\hline
\end{tabular}


Table 4 Relationship between irAE category and preexisting bood examination

\begin{tabular}{llll}
\hline & positive & negative & $p$ value \\
\hline Skin Toxicity & & & \\
anti Tg Ab & $0.9(0.9-11.0)$ & $0.9(0.9-0.9)$ & 0.06 \\
number & 37 & 162 & \\
antiTPOAb & $11.0(8.0-12.0)$ & $11.0(9.0-13.0)$ & 0.31 \\
$\mathrm{n}$ & 31 & 142 & \\
Thyroidtoxicity & & & \\
anti Tg Ab & $0.9(0.9-11.0)$ & $0.9(0.9-0.9)$ & 0.05 \\
$\mathrm{n}$ & 24 & 175 & \\
antiTPOAb & $11.0(8.8-13.3)$ & $11.0(9.0-12.5)$ & 0.55 \\
$\mathrm{n}$ & 16 & 155 & 0.02 \\
TSH & $2.40(1.37-3.97)$ & $1.51(0.92-2.60)$ & \\
$\mathrm{n}$ & 33 & 200 & 0.79 \\
FreeT3 & $2.37 \pm 0.54$ & $2.37 \pm 0.50$ & \\
$\mathrm{n}$ & 33 & 217 & 0.02 \\
FreeT4 & $0.98(0.89-1.13)$ & $1.06(0.95-1.16)$ & \\
$\mathrm{n}$ & 33 & 200 & \\
Pneumonitis & & 2868 & \\
KL6 & $274.5(183.5-341.5)$ & $283.0(186.0-455.5)$ & \\
$\mathrm{n}$ & 22 & 200 & \\
\hline
\end{tabular}

between lung cancer and other cancer types. The incidence of liver disorders was higher in patients with gastric cancer than in those with lung cancer $(P=0.04)$. The observed grade 3 and higher adverse events were pneumonia, liver disorder, encephalitis and skin disorders. Although all patients with these adverse events had been hospitalised and treated with steroids, those with pneumonia and encephalitis subsequently died. Table 5 shows the outcomes of patients with high-grade adverse events. Of the 115 patients with grade 1 and 2 irAEs, 88 (76.5\%) had discontinued ICI therapy and were treated with topical steroids and oral anti-histamines. ICI therapy was subsequently resumed and continued.

\section{Discussion}

ICIs have been reported to be effective in treating various types of cancers. Although this provides great hope for patients, the response rates are low. Thus, studies are being conducted to identify biomarkers that can be used to predict therapeutic effects $[15,16]$. Although PD-L1 is used clinically in patients with lung cancer, its effects have not been reproduced in other types of cancers. Recent studies have suggested that tumour mutation burden and microsatellite instability-high (MSI-H) can be used as biomarkers to predict the therapeutic effects. However, they are far from being established as biomarkers for some types of cancers. In recent years, several reports have indicated that the onset of irAEs is associated with the therapeutic effects in lung cancer, malignant melanoma and gastric cancer. However, these reports are based on small cohort studies with a dozen of patients because ICIs are infrequently used. In the present large-scale study involving 280 patients, we evaluated the association between irAEs and therapeutic effects, searched for predictive factors for the onset of irAEs and examined whether irAE profiles differ among cancer types. In this study, the overall incidence of treatment-associated adverse events was $41.1 \%$, which was comparable with the previously reported incidence $[5,8,9,12]$. The most common adverse events were skin disorders. In particular, a rash accompanied by dry skin and pruritus was frequently observed. However, grade 3 and higher skin disorders were observed in only two

Table 5 Treatment outcome of severe irAE patients

\begin{tabular}{|c|c|c|c|c|c|c|c|c|c|c|}
\hline organ & irAE detail & grade & origin & $\begin{array}{l}\text { time to } \\
\text { last } \mathrm{ICl}\end{array}$ & $\begin{array}{l}\text { Time to } \\
\text { first } \mathrm{ICl}\end{array}$ & treatment & outcome & reteatment & complication & $\begin{array}{l}\text { preexisting } \\
\text { antibody }\end{array}$ \\
\hline skin & $\begin{array}{l}\text { whole body } \\
\text { prurigo }\end{array}$ & 3 & lung & 21 & 69 & $\begin{array}{l}\text { steroid } \\
\text { po\&ointment }\end{array}$ & remission & try & none & $\mathrm{RF}$ \\
\hline skin & $\begin{array}{l}\text { whole body } \\
\text { prurigo }\end{array}$ & 3 & lung & 12 & 12 & $\begin{array}{l}\text { steroid po, } \\
\text { ointment \&iv }\end{array}$ & remission & stop & none & $\begin{array}{l}\text { TgAb,TPO, } \\
\text { RF, ANA }\end{array}$ \\
\hline Liver & $\begin{array}{l}\text { elevated liver } \\
\text { enzyms }\end{array}$ & 3 & renal & 21 & 21 & steroid po & remission & PD & none & ANA \\
\hline pneumonitis & $\begin{array}{l}\text { interstitial } \\
\text { pneumonia }\end{array}$ & 4 & lung & 3 & 3 & $\begin{array}{l}\text { systemic pulse } \\
\text { steroid }\end{array}$ & death & stop & $\begin{array}{l}\text { dyalisis, } \\
\text { lymphangitis }\end{array}$ & ANA \\
\hline pneumonitis & $\begin{array}{l}\text { interstitial } \\
\text { pneumonia }\end{array}$ & 4 & gastric & 16 & 140 & $\begin{array}{l}\text { systemic pulse } \\
\text { steroid }\end{array}$ & death & PD & none & \\
\hline pneumonitis & $\begin{array}{l}\text { interstitial } \\
\text { pneumonia }\end{array}$ & 3 & lung & 7 & 31 & $\begin{array}{l}\text { systemic pulse } \\
\text { steroid }\end{array}$ & & PD & none & \\
\hline CNS & convulsion & 5 & $\begin{array}{l}\text { malignant } \\
\text { melanoma }\end{array}$ & 17 & 43 & $\begin{array}{l}\text { systemic pulse } \\
\text { steroid }\end{array}$ & death & stop & brain meta RTx & \\
\hline thyroid & hyposthenia & 3 & gastric & 10 & 68 & steroid po & remission & try & none & ANA \\
\hline
\end{tabular}


patients. In terms of severity, many patients with skin disorders could be treated with moisturising agents, oral anti-histamines and topical steroids. The skin disorders were not associated with eosinophil or lymphocyte counts. The second most common irAE was thyroid disorders. Thyroid disorders appeared in two patterns. In one pattern, the thyroid function was transiently enhanced by acute thyroiditis, followed by hypothyroidism. In the other pattern, hypothyroidism was detected in regular blood tests. Peiro et al. also reported similar findings [17]. Although Toi et al. [18, 19] and Maekura et al. [20] reported that thyroid peroxidase (TPO) antibody and thyroglobulin antibody (TgAb) levels before ICI therapy were predictive factors for the development of hypothyroidism, whereas our study showed no association with TPO antibody levels but suggested an association with TgAb levels $(P=0.05)$. Meanwhile, a high TSH level before treatment appeared to be a possible predictive factor for the development of hypothyroidism. Interstitial pneumonia occurred in approximately $7.3 \%$ of all patients and $3.4 \%$ of patients with gastric cancer, and its incidence tended to be even higher in patients with head and neck cancer and lung cancer. This higher incidence rate appeared to be associated with respiratory symptoms and ease of accidental ingestion. Hori et al. [21] also reported that skin disorders and pneumonia accounted for approximately $17.8 \%$ of adverse events in patients treated for head and neck cancer, which is consistent with our findings. The observed serious adverse events of grade 3 and higher were pneumonia, encephalitis, liver disorder and skin disorders. All patients with these serious adverse events were hospitalised and treated with steroids. Among them, two patients with pneumonia did not respond to pulse therapy and died. Regarding therapeutic effects, the ORR was significantly higher in the irAE group, and this was reproducible in a larger number of patients with either gastric or lung cancer. In addition, similar results were obtained for OS and PFS. Masuda et al. [12]., who examined patients with gastric cancer, reported that PFS was extended by ICI therapy, which is consistent with our study. Also Masuda et al. [12] reported in this paper, according to the waterfall plot showing tumour regression rates, all patients with a high rate had developed irAEs. Because significant differences were observed all in ORR, PFS and OS, pre-treatment tests themselves that allow the prediction of irAE onset may be possible biomarkers. In the present study, the comparison between patients with and without irAEs showed a significant difference only in LDH levels. By disorder, hypothyroidism was associated with high TSH and TgAb levels. This suggested that, in patients who already have hypothyroidism before ICI therapy, regardless of being symptomatic or asymptomatic, the probability of exacerbation after therapy could be estimated. Interstitial pneumonia was not associated with Krebs von den Lungen-6 (KL-6) levels at all. However, in some patients with pneumonia, KL-6 levels that were elevated after the onset of pneumonia were decreased following the treatment of pneumonitis, which suggested that KL-6 levels might be meaningful for the purpose of evaluating therapeutic effects. Identifying biomarkers for predicting the onset of irAEs is an issue that should be addressed in future studies [22]. Even among patients with irAEs, many of them resumed ICI therapy after treatment of these irAEs. It appeared that the continuation of ICI therapy, along with early detection and adequate control of irAEs, might contribute to the improved prognosis of patients.

The present study is a retrospective study, including patients with different treatment backgrounds; thus, it contains several confounding factors, which is a limitation. A larger scale prospective study, in addition to a search for biomarkers for predicting the onset of irAEs, should be conducted in the future.

\section{Conclusion}

Although the onset of irAEs was difficult to be predicted based on pre-treatment tests. It appeared that the continuation of ICI therapy, along with early detection and adequate control of irAEs, might contribute to the improved prognosis of patients.

\section{Abbreviations \\ ICl: Immune checkpoint inhibitor; PD-1: Programmed cell death protein-1; irAE: Immune-related adverse event; CTC-AE: Common Terminology Criteria for Adverse Events; PFS: Progression-free survival; OS: Overall survival; TSH: Thyroid-stimulating hormone; TPO: Thyroid peroxidase antibody; TgAb: Thyroglobulin antibody; ANA: Antinuclear antibody; RF: Rheumatoid factor}

\section{Acknowledgements}

We appreciate the participation of patients and their families.

\section{Authors' contributions}

HM made substantial contribution to the designed the study. KT made substantial acquisition the data. TH performed the statistical analyses. KI, RS, $\mathrm{NO}, \mathrm{KS}, \mathrm{KK}, \mathrm{AS}, \mathrm{KM}, \mathrm{YA}$ and IU have contributed to the acquisition of data and revision of the manuscript. H.M. drafted the manuscript and all authors revised the manuscript and approved the final manuscript for publication.

\section{Funding}

This research did not receive any specific grant from funding agencies in the public, commercial, or not-for-profit sectors.

\section{Availability of data and materials}

The research data will not to be used for other purpose.

The datasets generated during the current study are not publicly available due to ethical restrictions, but are available from the corresponding author on reasonable request.

\section{Ethics approval and consent to participate}

The institutional review boards and Medical ethics committee at the Fujita Health University reviewed and approved the study (HM19-209), and Information was provided to patients participating in the study by posting on the hospital website and opt-out. Institutional review board approved the use of opt-out consent. The data used in this study was anonymised before its use. 


\section{Consent for publication}

Not Applicable.

This manuscript does not contain any individual person's data in any form.

\section{Competing interests}

The authors declare no conflict of interest.

\section{Author details}

${ }^{1}$ Department of Surgery Fujita Health University, Dengakugakubo 1-98, Kutsukake-cho, Toyoake City, Aichi, Japan. ${ }^{2}$ College of Pharmacy, Kinjo Gakuin University, 2-1723 Oomori Moriyama, Nagoya City, Aichi 463-8521, Japan. ${ }^{3}$ Department of Respiratory Medicine Fujita Health University, Dengakugakubo 1-98, Kutsukake-cho, Toyoake City, Aichi, Japan. ${ }^{4}$ Department of Urology Fujita Health University, Dengakugakubo 1-98, Kutsukake-cho, Toyoake City, Aichi, Japan. ${ }^{5}$ Department of Gastroenterology Fujita Health University, Dengakugakubo 1-98, Kutsukake-cho, Toyoake City, Aichi, Japan. ${ }^{6}$ Department of Dermatology Fujita Health University, Dengakugakubo 1-98, Kutsukake-cho, Toyoake City, Aichi, Japan.

${ }^{7}$ Department of Clinical Oncology Fujita Health University, Dengakugakubo 1-98, Kutsukake-cho, Toyoake City, Aichi, Japan. ${ }^{8}$ Fujita Health University International Medical Center, Dengakugakubo 1-98, Kutsukake-cho, Toyoake City, Aichi, Japan. ${ }^{9}$ Department of Pharmacy Fujita Health University, Dengakugakubo 1-98, Kutsukake-cho, Toyoake City, Aichi, Japan.

Received: 9 March 2020 Accepted: 6 July 2020

Published online: 14 July 2020

\section{References}

1. Kang YK, Boku N, Satoh T, Ryu MH, Chao Y, Kato K, et al. Nivolumab in patients with advanced gastric or gastro-oesophageal junction cancer refractory to, or intolerant of, at least two previous chemotherapy regimens (ONO-4538-12, ATTRACTION-2): a randomised, double-blind, placebocontrolled, phase 3 trial. Lancet. 2017:390:2461-71.

2. Gong J, Chehrazi-Raffle A, Reddi S, Salgia R. Development of PD-1 and PD-L1 inhibitors as a form of cancer immunotherapy: a comprehensive review of registration trials and future considerations. J Immunother Cancer. 2018:6:8.

3. Liu Y, Zhang T, Gao Y, Qu Y, Lu B, Zhang H, et al. A Single Center Analysis of Advanced Non-small Cell Lung Cancer Patients Treated with Immunotherapy in Real-world Practice. Zhongguo fei ai za zhi = Chinese journal of lung cancer. 2019;22:687-95.

4. Myers $\mathrm{G}$. Immune-related adverse events of immune checkpoint inhibitors: a brief review. Curr Oncol. 2018;25:342-7.

5. Zhou J, Wang H, Guo X, Wang Q, Duan L, Si X, et al. Management of immune checkpoint inhibitor-related rheumatic adverse events. Thoracic Cancer. 2019;11(1):198-202.

6. Spain L, Diem S, Larkin J. Management of toxicities of immune checkpoint inhibitors. Cancer Treat Rev. 2016:44:51-60.

7. Wang DY, Johnson DB, Davis EJ. Toxicities associated with PD-1/PD-L1 blockade. Cancer J. 2018:24:36-40.

8. Xing $P$, Zhang F, Wang G, Xu Y, Li C, Wang S, et al. Incidence rates of immune-related adverse events and their correlation with response in advanced solid tumours treated with NIVO or NIVO+IPI: a systematic review and meta-analysis. J Immunother Cancer. 2019;7:341.

9. Aso M, Toi Y, Sugisaka J, Aiba T, Kawana S, Saito R, et al. Association between skin reaction and clinical benefit in patients treated with antiprogrammed cell death 1 Monotherapy for advanced non-small cell lung Cancer. Oncologist. 2019;25(3):e536-e544.

10. Das S, Johnson DB. Immune-related adverse events and anti-tumor efficacy of immune checkpoint inhibitors. J Immunother Cancer. 2019;7:306.

11. Lau KS, Liu R, Wong CC, Siu WKS, Yuen KK. Clinical outcome and toxicity for immunotherapy treatment in metastatic cancer patients. Ann Palliat Med. 2019:apm.2019.10.03.

12. Masuda K, Shoji H, Nagashima K, Yamamoto S, Ishikawa M, Imazeki $H$, et al. Correlation between immune-related adverse events and prognosis in patients with gastric cancer treated with nivolumab. BMC Cancer. 2019;19:974

13. Okada N, Kawazoe H, Takechi K, Matsudate Y, Utsunomiya R, Zamami Y, et al. Association between immune-related adverse events and clinical efficacy in patients with melanoma treated with Nivolumab: a multicenter retrospective study. Clin Ther. 2019;41:59-67.
14. Brahmer JR, Lacchetti C, Schneider BJ, et al. Management of ImmuneRelated Adverse Events in Patiens treated with immune checkpoint inhibitor therapy: American Society of Clinical Oncology clinical guideline. CO. 2018:36:1714-68

15. Azuma Y, Nakaya A, Fujita S, Satake A, Nakanishi T, Tsubokura Y, et al. Neutrophil-to-lymphocyte ratio (NLR) fails to predict outcome of diffuse large B cell lymphoma. Leukemia Res Rep. 2019;12:100173.

16. Nakamura Y. Biomarkers for immune checkpoint inhibitor-mediated tumor response and adverse events. Front Med. 2019;6:119.

17. Peiro I, Palmero R, Iglesias P, Diez JJ, Simo-Servat A, Marin JA, et al. Thyroid dysfunction induced by nivolumab: searching for disease patterns and outcomes. Endocrine. 2019;64:605-13.

18. Toi Y, Sugawara S, Kawashima Y, Aiba T, Kawana S, Saito R, et al. Association of Immune-Related Adverse Events with clinical benefit in patients with advanced non-small-cell lung Cancer treated with Nivolumab. Oncologist. 2018:23:1358-65.

19. Toi Y, Sugawara S, Sugisaka J, Ono H, Kawashima Y, Aiba T, et al. Profiling preexisting antibodies in patients treated with anti-PD-1 therapy for advanced non-small cell lung Cancer. JAMA Oncol. 2019:5:376-83.

20. Maekura T, Naito M, Tahara M, Ikegami N, Kimura Y, Sonobe S, et al. Predictive factors of Nivolumab-induced hypothyroidism in patients with non-small cell lung Cancer. In vivo. 2017:31:1035-9.

21. Hori R, Shinohara S, Kojima T, Kagoshima H, Kitamura M, Tateya I, et al. Realworld outcomes and prognostic factors in patients receiving Nivolumab therapy for recurrent or metastatic head and neck carcinoma. Cancers. 2019:6:11.

22. Patil PD, Burotto $M$, Velcheti V. Biomarkers for immune-related toxicities of checkpoint inhibitors: current progress and the road ahead. Expert Rev Mol Diagn. 2018;18:297-305

\section{Publisher's Note}

Springer Nature remains neutral with regard to jurisdictional claims in published maps and institutional affiliations.

Ready to submit your research? Choose BMC and benefit from:

- fast, convenient online submission

- thorough peer review by experienced researchers in your field

- rapid publication on acceptance

- support for research data, including large and complex data types

- gold Open Access which fosters wider collaboration and increased citations

- maximum visibility for your research: over $100 \mathrm{M}$ website views per year

At $\mathrm{BMC}$, research is always in progress.

Learn more biomedcentral.com/submissions 